\title{
Time for change in Portuguese science
}

Sir - There is an almost perfect positive relationship between scientific output and gross domestic product (GDP) in Western Europe (Fig. 1). But two countries Ireland and Portugal — spoil the relationship.

Ireland, wisely, shows intense scientific activity, unlike Portugal, which publishes three times less than would be expected for its GDP. The general relationship between number of papers published and GDP is also true for the social sciences, and the arts and humanities (not shown), and the gap between observed and expected output for Portugal is just as wide.

The situation in Portugal requires immediate action if the country is to be ready to face the next century in an increasingly competitive world, where science and technology provide the driving force. Scientific output is almost exclusively correlated to spending on research and development (R\&D) $(r=0.949$ for the countries in Fig. 1). Portugal spends only 0.60 per cent of GDP on $R \& D$, whereas the rest of Western Europe spends on average 1.78 per cent of GDP. At the present rate of increase in spending on $R \& D$, it will be 50 years before Portugal reaches the current European average.

More funds need to be invested in Portuguese science and higher education. But a consistent policy and pooling of existing resources is also required. Small groups with good scientific potential should be brought together to create a critical mass and provided with a good scientific infrastructure coupled with regular evaluation of achievement. Longerterm funding should be provided instead of the current system based on irregular calls for project applications. To be fair to the present government, steps have been taken in the right direction, with the evaluation last year of research units by international experts and the introduction of some basic long-term funding. The government has also, correctly, put emphasis on preprimary and up to secondary school level education. It is now time to concentrate on higher education and research, paving the way for future generations.

A dramatic change in the university system, where most Portuguese science is carried out, is also required. Learning science in the universities has been undermined by chronic low funding (the annual cost of an undergraduate student in Portugal is 2.5 times less than in the United Kingdom), lack of basic equipment, ludicrous financial and accountancy rules, poor libraries and excessive teaching loads for lecturers. Universities have started some

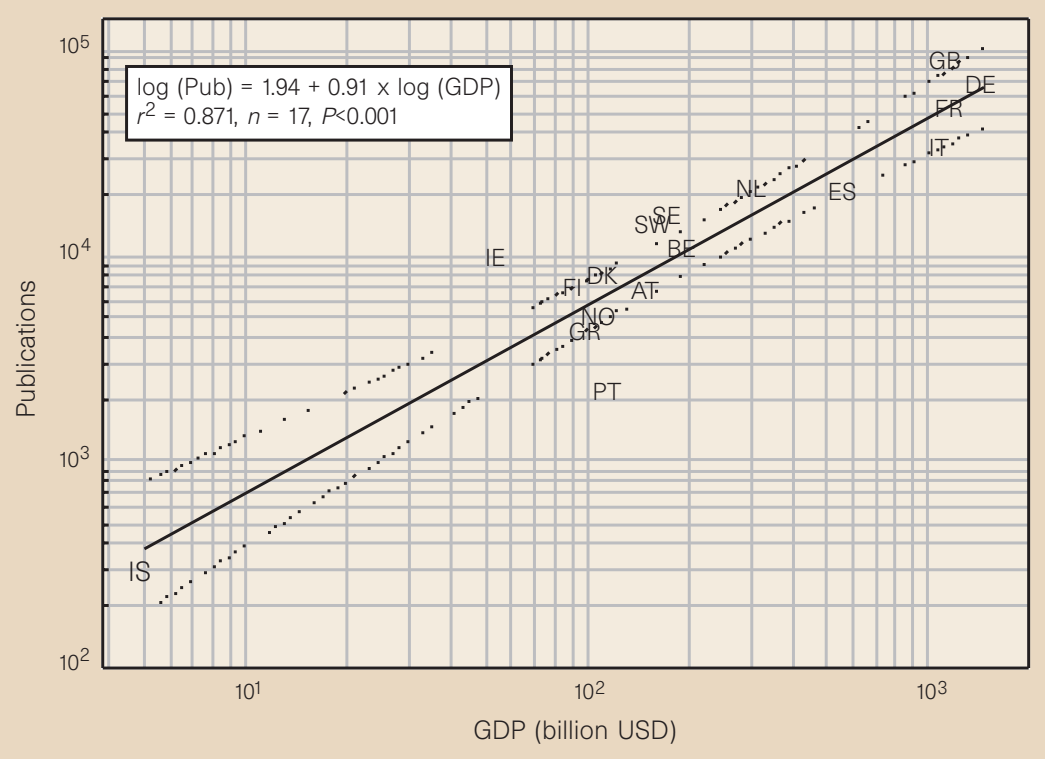

Figure 1 Scientific output in 1996 in Western Europe as a function of GDP in 1995. Dotted lines are $95 \%$ confidence limits of regression line. Data from: Science Citation Index (Institute of Scientific Information) and The World Fact Book (US Central Intelligence Agency). AT, Austria; BE, Belgium; DE, Germany; DK, Denmark; ES, Spain; FI, Finland; FR, France; GB, United Kingdom; GR, Greece; IE, Ireland; IS, Iceland; IT, Italy; NL, Netherlands; NO, Norway; PT, Portugal; SE, Sweden; SW, Switzerland.

sort of self-evaluation but have been showing little enthusiasm in the process.

There is also an indescribable and unique demagogic university autonomy system in which undergraduate students and teaching assistants (PhD students) hold up to 70 per cent of the vote for the election of rectors and heads of faculty. Lecturers and professors hold only 20 per cent of the vote, the other 10 per cent being held by administrative and support staff.

In this climate, planning is almost impossible, irrespective of the amount of funding. It is time for change. Otherwise, Portugal will continue for decades at the tail of scientific and academic achievement. Five hundred years ago, technology gave the Portuguese advantage over other countries, something that we like to boast about.

Adelino V. M. Canario

Centre of Marine Sciences,

University of Algarve,

8000 Faro,

Portugal

email:acanario@ualg.pt

\section{Quid pro quo}

Sir - The Dearing proposals on education in the United Kingdom, although not unreasonable in themselves, carry a serious threat to the recruitment of able postgraduate students working for higher degrees. Not only do such students represent the next generation of research workers but their work contributes very significantly to research in progress.

Yet their career prospects are not such as to put them in a position to repay the debt they will have accumulated to cover the cost of their undergraduate education; postgraduate education involves a further period of relative penury with no guaranteed prospects of a tenured appointment when completed.
It would be in the interests of Britain to cancel the debts of such students on their gaining a $\mathrm{PhD}$ in an approved field of study within a reasonable time limit, and perhaps also of those who serve a satisfactory apprenticeship in medicine or teaching. This would not be very costly because the numbers are relatively small, and it would act as a spur to recruitment and the completion of their theses.

Perhaps also the United Kingdom should think of designating some of its universities as exclusively postgraduate institutes along the lines of Princeton.

John A. Davis

1 Cambridge Road,

Great Shelford,

Cambridge CB3 5JE, UK 